\title{
Fibrinogen Lima: a Homozygous Dysfibrinogen with an A $\alpha$-Arginine-141 to Serine Substitution Associated with Extra N-Glycosylation at A $\alpha$-Asparagine-139 Impaired Fibrin Gel Formation but Normal Fibrin-facilitated Plasminogen Activation Catalyzed by Tissue-Type Plasminogen Activator
}

\author{
Hisato Maekawa, Kensuke Yamazumi, Shin-ichi Muramatsu, Munekiyo Kaneko, Hajime Hirata," Noriko Takahashi," \\ Carmen L. Arocha-Piñango, selva Rodriguez," Helena Nagy," Jose L. Perez-Requejo," and Michio Matsuda \\ Division of Hemostasis and Thrombosis Research, Institute of Hematology, and *Department of Biochemistry, Jichi Medical School, \\ Tochigi 329-04, Japan; ${ }^{\ddagger}$ Nagoya City University College of Nursing, Aichi 467, Japan; ${ }^{\S}$ Instituto Venezolano de Investigaciones \\ Cientificas, Caracas, Venezuela; "Hospital Perez Carreno, Caracas, Venezuela; and 'Banco de Sangre del Estado Carabobo, \\ Valencia, Venezuela
}

\begin{abstract}
An A $\alpha$-arginine-141 to serine substitution has been identified in a homozygous dysfibrinogen, fibrinogen Lima, associated with impaired fibrin polymerization. The point mutation created an asparagine- $X$-serine-type glycosylation sequence, and indeed, extra, mainly disialylated biantennary oligosaccharides have been isolated from $A \alpha$ asparagine-139 of the patient's fibrinogen. This type of glycosylation sequence is unique for human fibrinogen, because the sequences shown for normal and abnormal fibrinogens are all asparagine- $X$-threonine types. The terminal sialic acids of the extra oligosaccharides seem to have largely contributed to the impaired fibrin gel formation, as evidenced by its correction to a near normal level by desialylation. Nevertheless, the polymerizing fibrin facilitated tissuetype plasminogen activator-catalyzed plasmin formation in a normal fashion, indicating that the initial two-stranded fibrin protofibrils had been constructed normally. Thus the impaired fibrin gel formation could be attributed to the delay in their subsequent lateral association, most probably because of the repulsive forces generated by the negative electric charge of the extra sialic acids. The substitution of a basic residue arginine to a noncharged residue serine may also have contributed to the impaired function in a similar manner or by steric hindrance in association with bulky extra oligosaccharide chains. ( $J$. Clin. Invest. 1992. 90:67-76.) Key words: amino acid substitution • congenital homozygous dysfibrinogen • extra asparagine-linked oligosaccharide • fibrin-facilitated plasminogen activation • lateral association of fibrin protofibrils
\end{abstract}

\section{Introduction}

Although the conversion of fibrinogen to fibrin has been extensively studied, there still remain a plethora of enigmas regard-

Portions of this work were presented at the 13 th Congress of the International Society on Thrombosis and Haemostasis, Amsterdam, The Netherlands, July 1991.

Address reprint requests to Dr. Matsuda, Division of Hemostasis and Thrombosis Research, Institute of Hematology, Jichi Medical Tochigi-ken 329-04, Japan.

Received for publication 28 May 1991 and in revised form 23 January 1992

J. Clin. Invest.

(C) The American Society for Clinical Investigation, Inc.

$0021-9738 / 92 / 07 / 0067 / 10 \$ 2.00$

Volume 90, July 1992, 67-76 ing the structure-function relationships for the ordered molecular interactions to form fibrin gels (1-4). For further analyses, structurally well-characterized abnormal molecules with impaired fibrin polymerization seem to serve as powerful tools.

In this article, we report a unique amino acid substitution in a congenital dysfibrinogen, fibrinogen Lima (5), of A $\alpha$ arginine-141 to serine accompanied by an extra oligosaccharide attached to A $\alpha$-asparagine-139 because of a newly created asparagine- $X$-serine-type consensus sequence for the asparagine-linked $\mathrm{N}$-glycosylation. Although fibrin gel formation proceeded very slowly, polymerizing fibrin bound tissue-type plasminogen activator ( $t-P A)^{1}$ and facilitated plasminogen activation catalyzed by t-PA in a normal fashion. On the basis of these findings, we discuss the structure-function relationships with special reference to the formation of fibrin protofibrils and their subsequent lateral association.

\section{Methods}

Blood was collected from the patient and her parents by clean venipuncture and immediately anticoagulated with 1:9 vol of $3.8 \%$ (wt/vol) trisodium citrate containing $5 \mathrm{mM}$ benzamidine- $\mathrm{HCl}$. Plasma was harvested by centrifugation at $3,000 \mathrm{~g}$ for $30 \mathrm{~min}$ at $4^{\circ} \mathrm{C}$.

Fibrinogen was purified by repeated $25 \%$ ammonium sulfate saturation after removal of fibronectin and plasminogen by passing the plasma through columns of gelatin-Sepharose CL-6B and lysine-Sepharose CL-6B connected in tandem, as described previously (6). The precipitated fractions were dissolved in $0.3 \mathrm{M} \mathrm{NaCl}$, dialyzed against the same solution, and stored at $-80^{\circ} \mathrm{C}$ until used. Fibrinogen fractions thus prepared were found to be $>95 \%$ pure as examined by SDSPAGE $(7,8)$. Portions of the fibrinogen fractions were further treated with an anti-factor XIII (subunit A) monoclonal antibody bound to protein A-Sepharose (Pharmacia AB, Uppsala, Sweden) to eliminate factor XIII, a trace contaminant, as described (9).

Plasminogen and blood coagulation factor XIII were prepared from normal pooled plasma as described elsewhere $(10,11)$. Two-chain, recombinant t-PA was donated by the Sumitomo Pharmaceutical Co., Ltd., Osaka, Japan. The t-PA was expressed in Chinese hamster ovary cells transfected with a cDNA clone for human t-PA derived from Bowes melanoma cells.

All chemicals and reagents were purchased from commercial sources and used without purification except where specified. Human thrombin purchased from Mochida Pharmaceutical Co., Tokyo, Japan, was further purified essentially according to Lundblad (12). An-

1. Abbreviations used in this paper: FPA and FPB, fibrinopeptides A and $B$; KIU, kallikrein inhibitor unit; t-PA, tissue-type plasminogen activator. 
crod, the purified fraction of a thrombin-like snake venom enzyme derived from Agkistrodon rhodostoma was a gift from Dr. Minoru Fukuda, Mochida Pharmaceutical Co., Tokyo, Japan.

Molecular weight standards (Prestained SDS-PAGE Standards, Bio-Rad Laboratories, Richmond, CA) included lysozyme $(16,000)$, soybean trypsin inhibitor $(24,000)$, carbonic anhydrase $(33,000)$, ovalbumin $(47,000)$, bovine serum albumin $(84,000)$, phosphorylase B $(110,000), \beta$-galactosidase $(116,500)$, and myosin $(205,000)$.

Absorption coefficients $\left(A_{1 \mathrm{~cm}}^{1 \%}\right.$ at $\left.280 \mathrm{~nm}\right)$ for calculating the protein concentration were 15.1 for fibrinogen (13); 11.8, 17.4, and 20.4 for the $\mathrm{A} \alpha, \mathrm{B} \beta$, and $\gamma$ chains of fibrinogen, respectively (14); 17.0 for plasminogen (15); and 13.8 for factor XIII (16).

Studies on purified fibrinogen and fibrin monomer aggregation. The clotting time of purified fibrinogen with either thrombin or ancrod in the absence or presence of $\mathrm{CaCl}_{2}$, and fibrin monomer aggregation monitored by absorbance at $350 \mathrm{~nm}$ were performed essentially as described elsewhere (9).

Release of fibrinopeptides A and B (FPA and FPB) was studied as follows: 0.05 National Institutes of Health (NIH) U of thrombin was added to $0.2-\mathrm{mg}$ aliquots of fibrinogen in $250 \mu \mathrm{l}$ of $20 \mathrm{mM}$ potassium phosphate, $\mathrm{pH} 6.8$, containing $0.135 \mathrm{M} \mathrm{NaCl}$ and 25 kallikrein inhibitor unit (KIU) of aprotinin (Ono Pharmaceutical Co., Ltd., Osaka, Japan). At various times of incubation at $37^{\circ} \mathrm{C}$, the reaction mixtures were heat-treated for $10 \mathrm{~min}$ at $100^{\circ} \mathrm{C}$ and the fibrin clots were removed by centrifugation at $12,000 \mathrm{rpm}$ for $10 \mathrm{~min} .200 \mu \mathrm{l}$ of the supernatant was subjected to HPLC essentially according to Kehl et al. (17), and the released peptides were plotted as a function of time to assess their release rates.

Thrombin binding to fibrin was studied essentially according to Haverkate et al. (18). Briefly, fibrinogen $(0.1 \mathrm{mg} / \mathrm{ml})$ was incubated with various concentrations of bovine thrombin $(10,20,30,40$, and 50 $\mathrm{nM}$ ) in $50 \mathrm{mM}$ Tris- $\mathrm{HCl}$, $\mathrm{pH} 7.4$, containing $0.1 \mathrm{M} \mathrm{NaCl}$ and $1 \%$ BSA. After $30 \mathrm{~min}$, the fibrin clots formed were precipitated by centrifugation for $10 \mathrm{~min}$ at $12,000 \mathrm{rpm}$ and the residual thrombin activity in the supernatant was measured. Namely, $20 \mu \mathrm{l}$ of the supernatant was diluted with $80 \mu \mathrm{l}$ of the buffer, and incubated with $100 \mu \mathrm{l}$ of $0.8 \mathrm{mM}$ S-2238 (H-D-phenyl-pipecoryl-arginyl-p-nitroanilide $\cdot 2 \mathrm{HCl}$, Kabi Vitrum $\mathrm{AB}$, Uppsala, Sweden) at $37^{\circ} \mathrm{C}$. The color produced was read by absorbance at $405 \mathrm{~nm}\left(A_{405}\right)$ at 1 -min intervals over a period of $20 \mathrm{~min}$. As control, fibrinogen was replaced with the buffer for each sample, and the thrombin bound to fibrin was calculated according to the following equation: $T_{\mathrm{b}}=T_{\mathrm{c}}\left(1-\Delta A_{405}\right.$ for the sample $/ \Delta A_{405}$ for the control) $\times 10$, where $T_{\mathrm{b}}$ is the amount of thrombin bound to fibrin (pmol/ $\mathrm{mg}$ ) and $T_{\mathrm{c}}$ is the initial thrombin concentration $(\mathrm{pmol} / \mathrm{ml})$ in each sample.

The subunit structures of fibrinogen and cross-linked fibrin mediated by activated factor XIII (factor XIIIa), and their plasmic degradation products were examined by SDS-PAGE according to Laemmli (7) using $7.5 \%$ or $10 \%$ separating gels and $4 \%$ stacking gels, or $8-25 \%$ gradient gels as specified. Plasmic degradation of fibrinogen and factor XIIIa-mediated cross-linking of fibrin were conducted essentially as described elsewhere $(9,19)$. Plasmic degradation of cross-linked fibrin was also analyzed by utilizing fibrinogen labeled with ${ }^{125}$ I by the lactoperoxidase method essentially according to the manual supplied by the manufacturer $\left(\mathrm{Na}^{125} \mathrm{I}\right.$ from Amersham Japan, Tokyo; the specific activities were $1.246 \times 10^{3} \mathrm{cpm} / \mathrm{mg}$ for the patient's and $2.023 \times 10^{3} \mathrm{cpm} /$ $\mathrm{mg}$ for normal fibrinogen). Briefly, $100 \mu \mathrm{g}$ of the patient's or normal ${ }^{125}$ I-fibrinogen, $0.04 \mathrm{U}$ of factor XIII, and 0.1 NIH U of thrombin in 1.0 $\mathrm{ml}$ of $20 \mathrm{mM}$ Tris- $\mathrm{HCl}, \mathrm{pH} 7.4$, containing $0.15 \mathrm{M} \mathrm{NaCl}$ and $5 \mathrm{mM}$ $\mathrm{CaCl}_{2}$ (TBS-Ca) were allowed to react for $16 \mathrm{~h}$ at $37^{\circ} \mathrm{C}$, and fibrin clots formed were separated by centrifugation at $12,000 \mathrm{rpm}$ for $10 \mathrm{~min}$. After washing three times with TBS-Ca, the fibrin clots were suspended in $1.0 \mathrm{ml}$ of TBS-Ca containing 1.0 Committee on Thrombolytic Agents (CTA) $U$ of plasmin and gently agitated at $37^{\circ} \mathrm{C}$ over a period of $60 \mathrm{~h}$. At various times of incubation, $10-\mu \mathrm{l}$ aliquots were removed for the measurement of radioactivity.

Carbohydrate staining of the mutant A $\alpha$ chain. Fibrinogen and its plasmic digests were analyzed for carbohydrate utilizing biotinylated concanavalin A (Pierce Chemical Co., Rockford, IL), as described previously (20). Briefly, fibrinogen and its plasmic digests were subjected to SDS-PAGE before or after reduction, and separated polypeptides in the gels were electrophoretically transferred at $60 \mathrm{~V}$ for $4 \mathrm{~h}$ to nitrocellulose membranes by means of an electroblot apparatus (Marysol Industry Co., Tokyo, Japan) with a cooling system. The transfer buffer consisted of $25 \mathrm{mM}$ Tris- $\mathrm{HCl}, \mathrm{pH} 8.3$, containing $0.192 \mathrm{M}$ glycine and $20 \%$ methanol. At the end of the transfer period, the nitrocellulose membranes were soaked for $1 \mathrm{~h}$ at $22^{\circ} \mathrm{C}$ in $10 \mathrm{mM}$ Tris- $\mathrm{HCl}, \mathrm{pH} \mathrm{7.4,}$ containing $0.15 \mathrm{M} \mathrm{NaCl}$ (TBS) and $3 \%(\mathrm{wt} / \mathrm{vol}$ ) bovine serum albumin (BSA), and then washed three times with TBS containing $0.3 \%$ BSA (TBS-BSA). The membranes were successively incubated with $10 \mu \mathrm{g} /$ $\mathrm{ml}$ biotinylated concanavalin A in TBS-BSA, rinsed three times with TBS-BSA, incubated with 1,500-fold diluted streptavidin-biotinylated horseradish peroxidase complex (Amersham Japan) for $1 \mathrm{~h}$, and finally rinsed three times with TBS-BSA.

Isolation of fragment $D_{1}$ from the plasmic digests of normal and patient-derived fibrinogen. $20 \mathrm{mg}$ each of normal and the patientderived fibrinogen was passed through a column of Sepharose 4B conjugated with anti-factor XIII subunit A $\gamma$-globulin, and digested with plasmin (a mixture of $200 \mu \mathrm{g}$ of plasminogen and 3,200 $\mathrm{U}$ of streptokinase, which had been incubated for $20 \mathrm{~min}$ at $37^{\circ} \mathrm{C}$ ) in $10 \mathrm{ml}$ of 20 $\mathrm{mM}$ Tris- $\mathrm{HCl}, \mathrm{pH} 7.4$, containing $0.15 \mathrm{M} \mathrm{NaCl}$ and $2 \mathrm{mM} \mathrm{CaCl}_{2}$ for 18 $\mathrm{h}$ at $37^{\circ} \mathrm{C}$. The reaction was terminated by the addition of $2,000 \mathrm{KIU}$ of aprotinin. The digests were passed through a lysine-Sepharose CL-6B column, dialyzed against $25 \mathrm{mM}$ Tris- $\mathrm{HCl}, \mathrm{pH} \mathrm{7.8}$, and subjected to chromatofocusing to isolate fragment $D_{1}$, as described previously (19).

Binding of $t-P A$ to fibrinogen and fibrin, and fibrin facilitation of $t-P A$-catalyzed activation of plasminogen. Binding of t-PA to fibrinogen and fibrin was studied as described previously (20). Briefly, microtiter plates were treated with $100 \mu \mathrm{l}$ per well of $2.5 \%$ glutaraldehyde, $\mathrm{pH}$ 9.5 , for $2 \mathrm{~h}$ at $22^{\circ} \mathrm{C}$, washed three times with distilled water, and conjugated with fibrinogen $\left(0.1 \mathrm{mg} / \mathrm{ml}, 100 \mu \mathrm{l}\right.$ per well) for $16 \mathrm{~h}$ at $4^{\circ} \mathrm{C}$. After washing three times with $50 \mathrm{mM}$ phosphate buffer, $\mathrm{pH} 7.4$, containing $0.1 \mathrm{M} \mathrm{NaCl}$, the plates for the binding of $\mathrm{t}$-PA to fibrinogen were blocked with $3 \%$ BSA for $2 \mathrm{~h}$ at $37^{\circ} \mathrm{C}$. The plates for the binding of t-PA to fibrin were treated with $1 \mathrm{NIH} \mathrm{U} / \mathrm{ml}$ thrombin in $1 \%$ BSA for $30 \mathrm{~min}$ at $37^{\circ} \mathrm{C}$, washed with $1 \% \mathrm{BSA}$, and blocked with $3 \% \mathrm{BSA}$ for $2 \mathrm{~h}$ at $37^{\circ} \mathrm{C}$. The plates thus treated were further washed three times with $1 \%$ BSA- $0.01 \%$ Tween 80 . Various amounts of ${ }^{125}$ I-labeled t-PA in $1 \%$ BSA- $0.01 \%$ Tween 80 were added to wells and allowed to stand for $1 \mathrm{~h}$ at $37^{\circ} \mathrm{C}$. The plates were finally washed three times with $1 \%$ BSA$0.01 \%$ Tween 80 and dried, and radioactivity in each well was counted in a $\gamma$-counter. Fibrin facilitation of t-PA-catalyzed activation of plasminogen was studied as follows: To $180 \mu$ l of a mixture of plasminogen two-chain t-PA and S-2251 (H-D-valine-leucine-lysine-p-nitroanilide, Kabi Vitrum AB) in $20 \mathrm{mM}$ Tris- $\mathrm{HCl}$, pH 7.4, containing $0.1 \mathrm{M} \mathrm{NaCl}$, $20 \mu$ of fibrin monomer in $20 \mathrm{mM}$ acetic acid was added (final concentrations: plasminogen, $0.8 \mu \mathrm{M}$; two-chain t-PA, $40 \mathrm{U} / \mathrm{ml}$; S-2251, 0.3 $\mathrm{mM}$; and fibrin monomer, $0.2 \mu \mathrm{M}$ ), and plasmin generation was monitored by the measurement of $A_{405}$ at 1-min intervals.

Separation of the fibrinogen A $\alpha$ chain and its lysyl endopeptidase digestion. The three subunit polypeptides of fibrinogen were separated after reduction and S-pyridylethylation by HPLC using a TMS-250 column ( $4.6 \times 75 \mathrm{~mm}$, Tosoh, Tokyo, Japan) as described previously (19). They were eluted in the order of $A \alpha, B \beta$, and $\gamma$ chains with a linear gradient of $20-50 \%$ acetonitrile in $60 \mathrm{~min}$. The pyridylethylated $\mathrm{A} \alpha$ chain $(\mathrm{Pe}-\mathrm{A} \alpha)$ was collected and lyophilized.

The Pe-A $\alpha(0.24 \mathrm{mg} / \mathrm{ml}, 240 \mu \mathrm{g})$ derived from the patient's fibrinogen was digested with lysyl endopeptidase (Wako Pure Chemical Industries Ltd., Osaka, Japan; enzyme/substrate ratio $=1: 100$, wt $/ \mathrm{wt}$ ) for $18 \mathrm{~h}$ at $37^{\circ} \mathrm{C}$ in $50 \mathrm{mM}$ Tris- $\mathrm{HCl}$, pH 9.0 , containing $3 \mathrm{M}$ urea. The digests were analyzed by reverse-phase HPLC with a Cosmosil 5C18P column $(4.6 \times 150 \mathrm{~mm})$ by applying a linear gradient of $0-60 \%$ of a solvent consisting of $0.1 \%$ trifluoroacetic acid/acetonitrile in $0.1 \%$ trifluoroacetic acid/water in $120 \mathrm{~min}$ as described elsewhere (19). The relevant peaks were collected and further purified by rechromatography on the same column. 
Amino acid sequence analysis. The purified aberrant peptide and its normal counterpart were analyzed for the primary sequence utilizing a gas-phase sequenator, model $470 \mathrm{~A}$ protein sequencer connected to a model 120A PTH analyzer (Applied Biosystems Japan, Tokyo, Japan) and model SP 4270 integrator (Spectra-Physics, San Jose, CA), essentially as described (21).

A 1-nmol portion of an aberrant peptide consisting of the $\mathrm{A} \alpha$ (139148) residues (indicated by an open star in Fig. 5 or peak 2 in its inset) in $148 \mu \mathrm{l}$ of $10 \mathrm{mM}$ citrate buffer, $\mathrm{pH} 6.0$ containing $10 \mathrm{mM} \mathrm{CaCl}_{2}$ was digested with $5 \mu$ l of glycopeptidase A from almond (Seikagaku Kogyo Co., Tokyo, Japan; $20 \mu \mathrm{U} / \mu \mathrm{l}$ ) essentially as described (22-24), and finally separated by the same column for sequence analysis. This was carried out to verify the presence of a potentially $\mathrm{N}$-glycosylated asparagine residue at position 139, which had not been identified without prior treatment with glycopeptidase A.

Analysis of N-linked oligosaccharide by HPLC. $4 \mathrm{nmol}$ each of the aberrant $\mathrm{A} \alpha(139-148)$ peptide and normal fibrinogen was treated with $1 \mu \mathrm{l}$ of glycopeptidase A $(20 \mu \mathrm{g} / \mu \mathrm{l})$ as described (22), and the reaction mixtures were directly applied on a CarboPac PA-1 column of the Bio-LC system by high performance anion-exchange column chromatography with pulsed-amperometric detection (Dionex Co., Sunnyvale, CA) essentially according to Townsend et al. (25).

Each separated fraction (the neutral, monosialylated, and disialylated oligosaccharide) was desialylated with sialidase from Arthrobacter ureafaciens free of any protease activity (Nacalai Tesque, Inc., Kyoto, Japan) and reductively aminated with 2 -aminopyridine and sodium cyanoborohydride by the method previously reported (24). The structures of pyridylamino oligosaccharides were confirmed by two-dimensional sugar mapping with two different HPLC columns, a reversephase column (Shim-pack CLC-ODS, Shimadzu Corp., Kyoto, Japan) and a size-fractionation column (TSK-Gel Amide-80, Tosoh), as described previously (23).

Desialidation of fibrinogen. $1 \mathrm{mg}$ of the patient's fibrinogen was dialyzed against $10 \mathrm{mM}$ citrate buffer, $\mathrm{pH} 5.0$, and treated with 1.77 $\mathrm{mU}$ of sialidase for $1 \mathrm{~h}$ at $37^{\circ} \mathrm{C}$. The reaction mixture was dialyzed against $20 \mathrm{mM}$ Tris- $\mathrm{HCl}, \mathrm{pH} \mathrm{7.4,} \mathrm{containing} 0.1 \mathrm{M} \mathrm{NaCl}$ and succes-

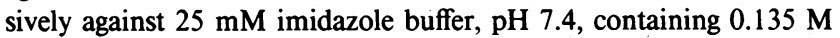
$\mathrm{NaCl}$. Normal fibrinogen was treated in the same way except for the treatment with sialidase, in which $1.0 \mathrm{mU}$ of the enzyme was used. The amount of enzyme was determined based on the content of sialic acid per mole of fibrinogen; i.e., $7.6 \mathrm{~mol}$ for the patient's and $4.3 \mathrm{~mol}$ for normal fibrinogen. At this enzyme/substrate ratio, $>98 \%$ of the sialic acids have been shown to be cleaved from the terminal galactose residues of N-linked oligosaccharides of normal fibrinogen (26). In fact, after the sialidase treatment, the mobility of the A $\alpha$ chain of the patient's fibrinogen $(\mathrm{A} \alpha)$ was uniformly reduced in the SDS-PAGE of Laemmli (7), suggesting satisfactory cleavage of the terminal sialic acids from the extra oligosaccharide (figures not shown).

\section{Results}

Description of the patient. The patient is a 10 -yr-old girl from Lima, Peru, who was originally reported to have an apparently homozygous dysfibrinogen with impaired fibrin polymerization (5). Briefly, her parents are first cousins and thought to have the same type of dysfibrinogen in the heterozygous form. Although a transient hematuria was noted in the patient, there was no history of bleeding or thrombosis related to this abnormality in the family. The abnormality of fibrinogen was discovered by the discrepancy between the plasma fibrinogen level determined by the thrombin time method of Clauss (27), 50 $\mathrm{mg} / 100 \mathrm{ml}$, and the gravimetric method (28), $240 \mathrm{mg} / 100 \mathrm{ml}$. Similar but less remarkable discrepancies were noted in the levels of plasma fibrinogen in her parents, i.e., 100 and 302 $\mathrm{mg} / 100 \mathrm{ml}$ for her father, and 150 and $240 \mathrm{mg} / 100 \mathrm{ml}$ for her mother as determined by the two methods, respectively. In spite of the complete identity with normal fibrinogen on immunodiffusion, the patient's fibrinogen migrated to a more anodal region on immunoelectrophoresis as compared with normal fibrinogen.

Furthermore, the $A \alpha$ chain of the patient's fibrinogen appeared to have a higher molecular weight than the normal A $\alpha$ chain when examined by SDS-PAGE. Other laboratory findings such as prolonged thrombin and Reptilase times and their partial correction by calcium, and impaired fibrin gel formation profiles after the addition of thrombin were all compatible with the findings known for the abnormal fibrinogens. Based on these data, we attempted to analyze the patient's fibrinogen for the structural alteration and its relation to the functional abnormalities.

Clotting of fibrinogen with thrombin or ancrod. As summarized in Table I, the clotting times of fibrinogen with thrombin and ancrod in the absence of calcium ions were both prolonged markedly in the propositus and moderately in her parents, as compared with those of normal fibrinogen. The addition of calcium apparently but not completely shortened the thrombin and ancrod times.

The release rates of FPA and FPB after the addition of thrombin were both normal, and the elution positions for these peptides were exactly identical with those for the normal counterparts (profiles not shown). The thrombin binding profile to the patient's fibrin was also identical with that to normal fibrin up to $50 \mathrm{nM}$ thrombin (profiles not shown). These data indicate that the initial step of fibrinogen to fibrin conversion proceeded normally in this dysfibrinogen.

The fibrin clots formed with thrombin in the presence of 5 $\mathrm{mM} \mathrm{CaCl}{ }_{2}$ were resistant against $6 \mathrm{M}$ urea.

The subunit polypeptides of fibrinogen and cross-linked $f$ brin, and their plasmic digestion analyzed by SDS-PAGE. As shown in Fig. 1, a higher molecular weight $\mathrm{A} \alpha$ chain $\left(\mathrm{A} \alpha^{\prime}\right)$ was noted in the patient's fibrinogen $(P)$ as compared with the normal counterpart $(N)$. Bands below the normal and abnormal $\mathrm{A} \alpha$ chains seem to represent the partially degraded $\mathrm{A} \alpha$ chains. In the samples derived from her parents (father $[F]$ and mother $[M]$ ) and a 1:1 mixture of normal and the patient's fibrinogens $(N+P)$, the $\mathrm{A} \alpha$ chain apparently consisted of both a normal $(\mathrm{A} \alpha)$ and an abnormal $\mathrm{A} \alpha$ chain species $\left(\mathrm{A} \alpha^{\prime}\right)$. These findings appeared to be consistent with the previous observation that the propositus was most probably a homozygote for the abnormality inherited from her heterozygous parents who were first cousins (5).

Several possibilities could be raised to account for the higher molecular weight for the abnormal A $\alpha$ chain, and linking to an extra oligosaccharide was thought to be a highly proba-

Table I. Thrombin and Ancrod Times of Fibrinogen Derived from the Patient and Her Parents

\begin{tabular}{lrrrr}
\multicolumn{1}{c}{ Studies } & Normal & Father & Mother & Patient \\
\hline Thrombin time $(s)$ & & & & \\
$\quad$ Without calcium ions & 12.2 & 25.6 & 24.2 & 38.4 \\
$\quad$ With calcium ions & 6.7 & 11.8 & 12.6 & 16.2 \\
Ancrod time $(s)$ & & & & \\
$\quad$ Without calcium ions & 11.5 & 19.4 & 20.2 & 28.4 \\
$\quad$ With calcium ions & 8.2 & 13.1 & 13.7 & 15.2 \\
& & & & \\
\hline
\end{tabular}




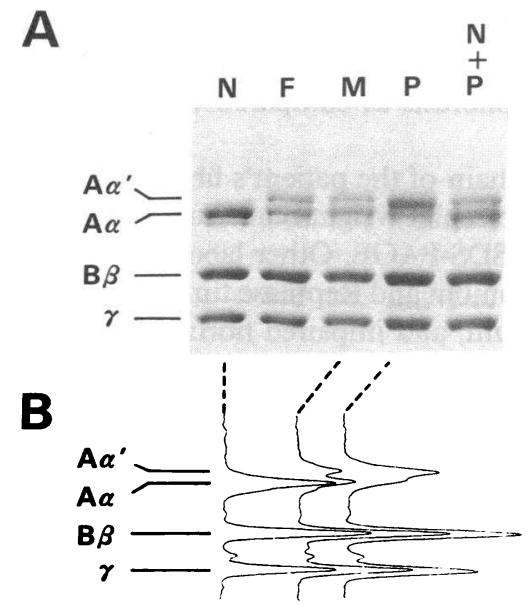

samples $F, M$, and $N+P$, the normal (A $\alpha)$ and the $\mathrm{A} \alpha^{\prime}$ chain species are both present. In these samples, the third band which represents the degraded normal $A \alpha$ chain is present. $10 \%$ Laemmli gels and Coomassie Brilliant Blue staining. $(B)$ Densitometric scanning of the separated polypeptides of representative samples.

ble candidate as has recently been shown in two other abnormal fibrinogens reported from this laboratory $(9,20)$. Indeed, the abnormal $\mathrm{A} \alpha$ chain was found to stain positively for carbohydrate with biotinylated concanavalin $\mathrm{A}$, whereas the normal A $\alpha$ chain, in which the carbohydrate moieties had been reported to be absent (29), was negative for the staining (Fig. $2 \mathrm{~B}$ ). By further studies with the plasmin-digests of patient-derived fibrinogen, the extra carbohydrate was located to the $\alpha$ chain remnant of fragment $\mathrm{D}_{1}\left(\alpha^{\prime} / D_{1}\right)$, as evidenced by a higher mol wt $\alpha$ chain remnant (Fig. $2 C$ ) that stained positively for carbohydrate (Fig. $2 D$ ) on $8-25 \%$ gradient gels. Except the higher molecular weight for the $A \alpha$ chain and its remnant in the plasmic digests, profiles of plasmic digestion (profiles not shown, but refer to Fig. 8 for the degradation of thrombin-activated
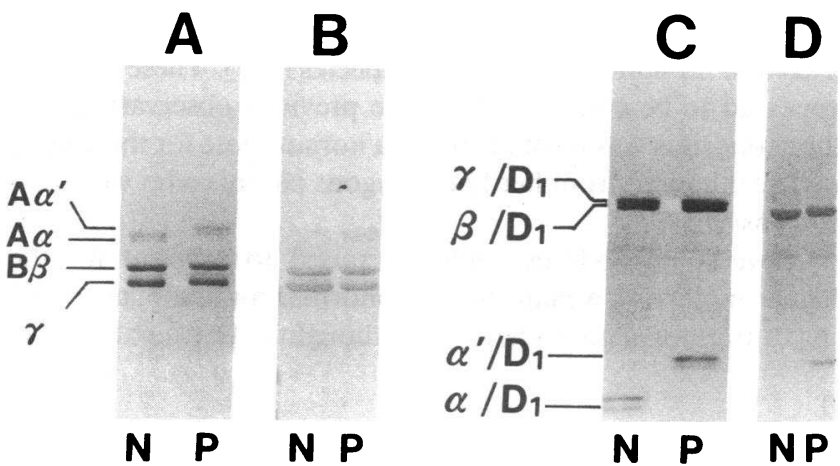

Figure 2. Analysis of the aberrant $A \alpha^{\prime}$ chain and its remnant in fragment $D_{1}$ by carbohydrate staining. The resolved subunits on SDSPAGE of fibrinogen and their remnants in fragment $D_{1}$ were electrophoretically transferred at $60 \mathrm{~V}$ for $4 \mathrm{~h}$ to nitrocellulose membranes, stained for carbohydrate with $10 \mu \mathrm{g} / \mathrm{ml}$ biotinylated concanavalin A and visualized by 1,500 -fold-diluted streptavidin-biotinylated horseradish peroxidase complex. For comparison, the samples stained for protein with Coomassie Brilliant Blue are shown. Subunits of fibrinogen and their remnants in fragment $\mathrm{D}_{1}$ stained for protein $(A$ and $C)$ and for carbohydrate $(B$ and $D) . N$, normal samples; $P$, patient-derived samples. fibrinogen by plasmin generated in its presence by t-PA-catalyzed plasminogen activation) and factor XIIIa-mediated cross-linking profiles examined by SDS-PAGE were essentially identical with those of the normal samples (profiles not shown). The plasmic digestion of ${ }^{125}$ I-labeled patient's fibrin as monitored by the release of radio label was also indistinguishable from that of the normal sample (profiles not shown).

Polymerization of fibrin monomer monitored by $A_{350}$. As depicted in Fig. $3 A$, polymerization of fibrin monomer in the absence of calcium ions was distinctly delayed for the propositus, whereas it was moderately impaired for her father. Although the lag phase was substantially shortened, similar trends of impaired polymerization were noted in the presence of calcium (Fig. $3 \mathrm{~B}$ ).

Inhibition of thrombin clotting of normal fibrinogen and normal fibrin monomer aggregation by isolated fragment $D_{1}$ derived from the patient's fibrinogen. Because the extra carbohydrate was located to the $\alpha$ chain remnant of fragment $D_{1}$, we tested whether or not fragment $D_{1}$ isolated from the patient's fibrinogen (fragment $D_{1}$ Lima) could inhibit thrombin clotting of normal fibrinogen and polymerization of normal fibrin monomer. As has been widely accepted, fragment $D_{1}$ contains a putative polymerization site specifically assigned to the $D$ domain, the " $a$ " site, which is complementary to the " $A$ " site exposed onto the central $E$ domain by the removal of FPA (30, 31 ). The addition of fragment $D_{1}$ Lima prolonged the thrombin clotting time of normal fibrinogen dose-dependently and in a normal fashion, namely, $14.6,19.6,49.8$, and $>300 \mathrm{~s}$ as compared with $14.6,20.2,56.2$, and $>300 \mathrm{~s}$ for normal fragment $D_{1}$ at the fragment $D_{1} /$ fibrinogen ratios of $0,1,2$, and 3 , respectively. As depicted in Fig. 4, addition of fragment $D_{1}$ Lima also inhibited polymerization of normal fibrin monomer in a dose-dependent manner and as effectively as normal fragment $D_{1}$, indicating that the putative "a" polymerization site was normally functional in this dysfibrinogen.

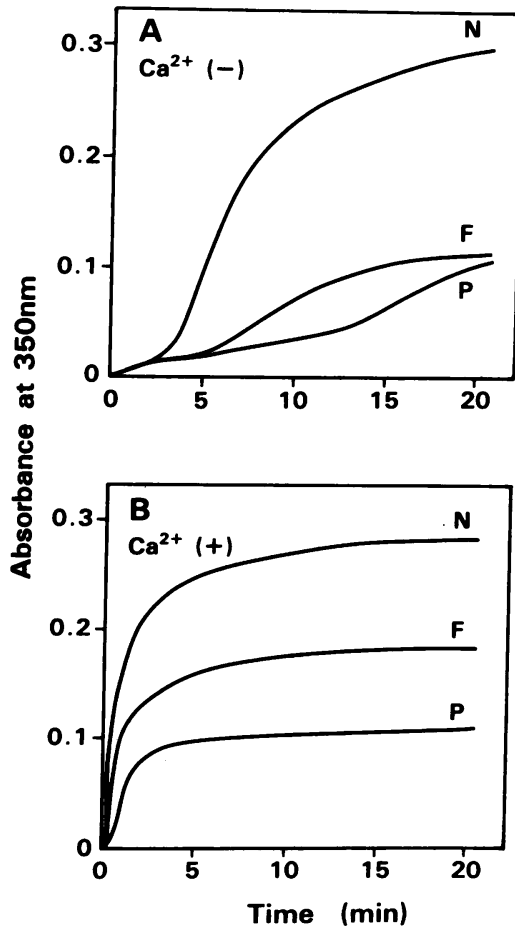

Figure 3. Polymerization profiles of fibrin monomer derived from the patient and her father. $20 \mu \mathrm{l}$ of fibrin monomer $(4 \mathrm{mg} / \mathrm{ml})$, prepared from thrombin-treated fibrinogen and dissolved in $20 \mathrm{mM}$ acetic acid, was diluted with $500 \mu \mathrm{l}$ of $60 \mathrm{mM}$ potassium phosphate, $\mathrm{pH} 6.8$, in the $(A)$ absence or the $(B)$ presence of $2 \mathrm{mM} \mathrm{CaCl}$. Fibrin polymerization was monitored by continuous measurement of $A_{350} . P$, the patient's; $F$, the father's; and $N$, normal fibrin monomer. 


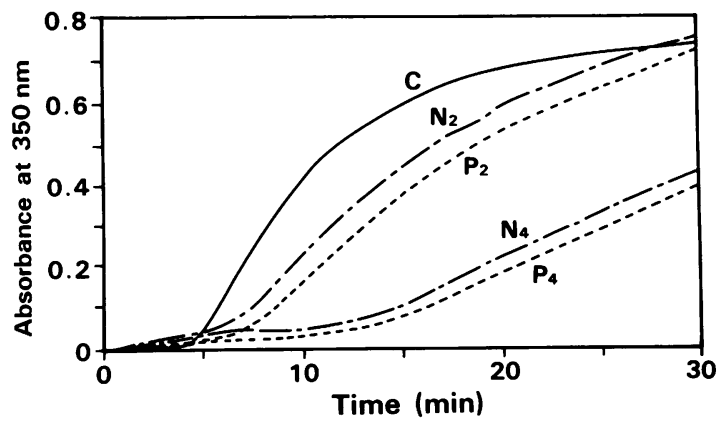

Figure 4. Inhibition of normal fibrin monomer polymerization by isolated fragment $D_{1} .20 \mu$ of fibrin monomer $(4 \mathrm{mg} / \mathrm{ml})$, was diluted with $500 \mu$ l of $60 \mathrm{mM}$ potassium phosphate, $\mathrm{pH} 6.8$, containing fragment $D_{1}$ derived from normal or the patient's fibrinogen. The molar ratios of normal $(N)$ or the patient's $(P)$ fragment $D_{1}$ to normal fibrin monomer were 2:1 $\left(N_{2}, P_{2}\right)$ and 4:1 $\left(N_{4}, P_{4}\right)$. Fibrin polymerization was monitored by continuous measurement of $A_{350}$. The control without the addition of fragment $\mathrm{D}_{1}$ is shown by curve $C$.

Analysis of amino acid substitution. We thus attempted to isolate the abnormal A $\alpha$ chain by reverse-phase HPLC after reduction and $S$-pyridylethylation, and digested it with lysyl endopeptidase. The digests were then fractionated on a Cosmosil $5 \mathrm{C} 18 \mathrm{P}$ column, and the peptides were eluted by a linear gradient of $0-60 \%$ acetonitrile in $120 \mathrm{~min}$. By comparison with the elution profile for a normal sample ( $N$ in Fig. 5), we identified an aberrant peptide in the patient's sample $(P)$ as indicated by an open star or peak $2^{\prime}$ in the inset, which was not present in the normal digests. Conversely, a peptide indicated by a closed star in the normal sample $(N)$ or peak 2 in the inset was missing in the patient's sample. In the sample derived from her father $(F)$, the relevant peaks were both present but reduced in the amount nearly a half as much as the corresponding peaks in the normal and the patient's samples, respectively (peaks 2 and $2^{\prime}$ in the inset). These results were compatible with the homozygosity of the patient and the heterozygosity of her father for this molecular abnormality.

Peaks 2 and 2', derived from the normal and patient's sample, respectively, were separately collected and analyzed for the primary sequence. Both peptides were found to consist of 10 amino acids corresponding to the $\mathrm{A} \alpha(139-148)$ residues, and an arginine residue at cycle 3 or position 141 was found to be replaced by a serine residue in the aberrant peptide, peak $2^{\prime}$ (Table II). An asparagine residue identified at the first cycle of the normal peptide was not observed in the aberrant peptide. This asparagine residue thus appeared to have been glycosylated and not to have been detected by the technique applied, because there was an asparagine- $X$-threonine/serine-type consensus sequence for $\mathrm{N}$-glycosylation, asparagine-valine-serine, newly created by the amino acid substitution. Therefore, we digested the aberrant peptide with glycopeptidase $A$ to remove carbohydrate, if any, and sequenced the resultant peptide (peak $\left.2^{\prime}-\mathrm{G}\right)$ after separation by reverse-phase HPLC. As had been expected, an aspartic acid residue was identified at cycle 1 certainly as a product derived from the $\mathrm{N}$-glycosylated asparagine upon hydrolysis of the $\beta$-aspartylglycosylamine linkage with the oligosaccharide. We thus concluded that arginine at position 141 of the A $\alpha$ chain of fibrinogen Lima had been replaced by serine and that asparagine at position $A \alpha-139$ had been consequently $\mathrm{N}$-glycosylated.

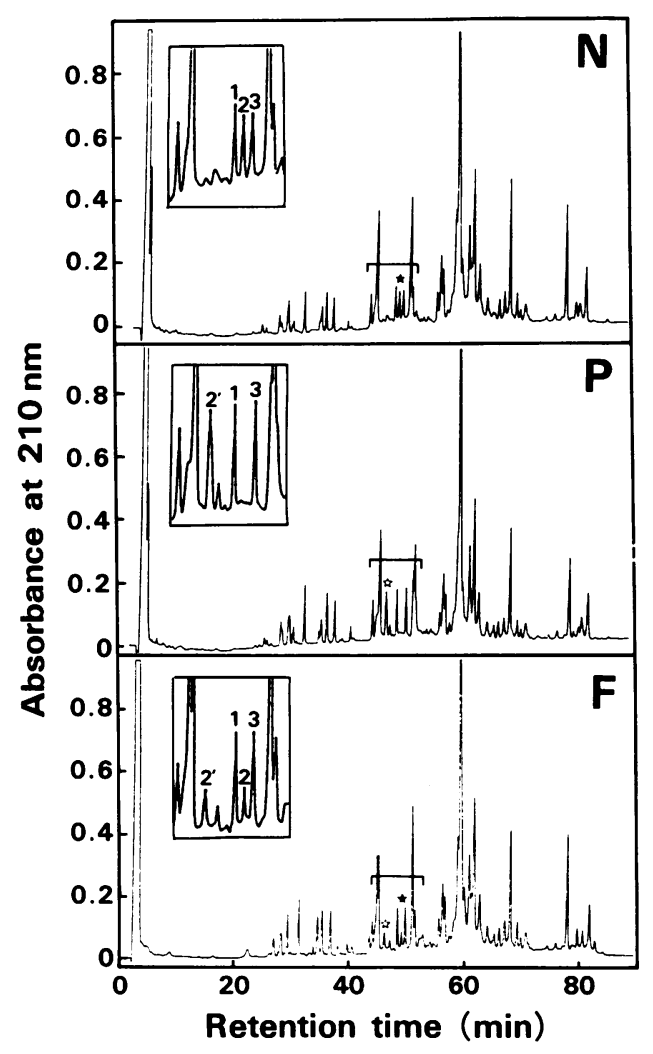

Figure 5. HPLC elution profiles of lysyl endopeptidase-digests of isolated $\mathrm{A} \alpha$ chains. The digests of pyridylethylated $\mathrm{A} \alpha$ chains derived from normal $(N)$, the patient's $(P)$, and her father's $(F)$ fibrinogen were injected onto a Cosmosil $5 \mathrm{C} 18 \mathrm{P}$ column $(4.6 \times 150 \mathrm{~mm})$, and the peptides were eluted by a linear gradient of $0-60 \%$ acetonitrile in $120 \mathrm{~min}$. A peptide peak indicated by a closed star in the normal sample or peak 2 in the inset is missing in the patient's sample, whereas an aberrant peak indicated by an open star or peak $2^{\prime}$ in the inset is present in the patient's sample. In the sample derived from the father, both peptide peaks are present in reduced amounts. These peptides were separately collected, further purified on the same column and subjected to amino acid sequence analysis.

Analysis of the extra oligosaccharide attached to A $\alpha-A s n-$ 139. To identify the structure of the extra oligosaccharide, we isolated the A $\alpha$ chain from the reduced and $S$-pyridylethylated patient's fibrinogen, treated it with glycopeptidase A, and separated the oligosaccharide therefrom by high performance anion-exchange column chromatography with pulsed-amperometric detection (for details, see Methods). For comparison, the oligosaccharide isolated from normal fibrinogen was studied. There were three major peaks for each sample, which corresponded to the neutral, monosialylated, and disialylated biantennary oligosaccharides, respectively (Fig. 6), and their basic structure was found to be galactose $(\mathrm{Gal})_{2} \cdot \operatorname{man}$ nose(Man $)_{3} \cdot \mathrm{N}$-acetyl glucosamine $(\mathrm{GlcNAc})_{4}$ as reported by Townsend et al. (25) (see the legend to Fig. 6). They were collected separately, desialylated, derivatized with 2-aminopyridine, and subsequently analyzed by two-dimensional sugar mapping (23) to confirm the oligosaccharide structure. The percent distribution of the oligosaccharides was calculated from the peak area based on the finding that the relative fluorescence intensity for each oligosaccharide was the same on the molar basis. As depicted in Fig. 6, the disialylated oligosaccharide was the most abundant $(68.6 \%)$ in the oligosaccharides 
Table II. Amino Acid Sequences of the Peak 2 Peptide, and Aberrant Peak 2' and its Glycopeptidase-treated Peak 2'-G Peptides

\begin{tabular}{|c|c|c|c|c|c|c|c|}
\hline \multirow[t]{2}{*}{ Cycle } & \multirow[t]{2}{*}{ Position } & \multicolumn{2}{|c|}{$\begin{array}{c}\text { Peak } 2 \\
\text { amino acid }\end{array}$} & \multicolumn{2}{|c|}{$\begin{array}{c}\text { Peak } 2^{\prime} \\
\text { amino acid }\end{array}$} & \multicolumn{2}{|c|}{$\begin{array}{l}\text { Peak 2'-G } \\
\text { amino acid }\end{array}$} \\
\hline & & & pmol & & pmol & & pmol \\
\hline 1 & 139 & Asn & 726 & $\mathrm{Nil}^{*}$ & & Asp & 43 \\
\hline 2 & 140 & Val & 760 & Val & 620 & Val & 172 \\
\hline 3 & 141 & Arg & 306 & Ser & $\mathrm{NQ}^{\ddagger}$ & Ser & $\mathrm{NQ}^{\ddagger}$ \\
\hline 4 & 142 & Ala & 544 & Ala & 370 & Ala & 119 \\
\hline 5 & 143 & Gln & 217 & Gln & 256 & Gln & 71 \\
\hline 6 & 144 & Leu & 147 & Leu & 170 & & $D^{\S}$ \\
\hline 7 & 145 & Val & 113 & Val & 120 & & $D^{\S}$ \\
\hline 8 & 146 & Asp & 87 & Asp & 52 & & $D^{\S}$ \\
\hline 9 & 147 & Met & 28 & Met & 48 & & $D^{\S}$ \\
\hline 10 & 148 & Lys & 9 & Lys & 31 & & $D^{\S}$ \\
\hline
\end{tabular}

Abbreviations: Ala, alanine; Asp, aspartic acid; Arg, arginine; Asn, asparagine; Gln, glutamine; Leu, leucine; Lys, lysine; Met, methionine; $\mathrm{Val}$, valine. ${ }^{*}$ No phenylthiohydantoin-derivative was identified. ${ }^{\ddagger}$ Not quantitated. ${ }^{\S}$ Not determined.

derived from the aberrant $\mathrm{A} \alpha$ chain, whereas the monosialylated one was the major component $(62.5 \%)$ in the normal fibrinogen-derived oligosaccharides.

Binding with $t-P A$ and fibrin-facilitated $t-P A$-catalyzed act $i$ vation of plasminogen. Because the structural alteration had been identified near a putative reactive site with t-PA assigned to the $\mathrm{A} \alpha$ chain, the $\mathrm{A} \alpha(148-160)$ residues (32), we examined whether the structural alteration would have affected the reac-

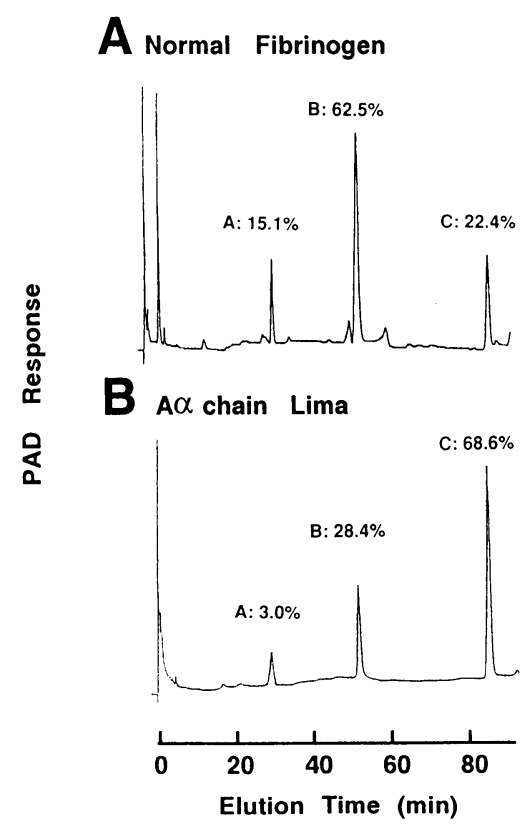

Figure 6. Analysis of oligosaccharides derived from normal fibrinogen $(A)$, and those from the aberrant $\mathrm{A} \alpha(139-148)$ peptide isolated from the patient's $\mathrm{Pe}-\mathrm{A} \alpha$ chain $(B)$ by high performance anion-exchange chromatography with pulsed-amperometric detection. Peak $A$, neutral; peak $B$, monosialylated at either of the terminal galactose residues; and peak $C$, disialylated oligosaccharides. PAD, pulsed-amperometric detection. The neutral oligosaccharide moiety was the biantennary structure as follows:

$\operatorname{Gal} \beta(1,4) \operatorname{GlcNAc} \beta(1,2) \operatorname{Man} \alpha(1,6)$ $\operatorname{Gal} \beta(1,4) \operatorname{GlcNAc} \beta(1,2) \operatorname{Man} \alpha(1,3){ }^{\searrow} \operatorname{Man} \beta(1,4) \operatorname{GlcNAc} \beta(1,4)-$ GlcNAc $\beta$-Asn

Gal, galactose; GlcNAc, $N$-acetylglucosamine; Man, mannose; and Asn, asparagine. tive site and have modified the t-PA-catalyzed plasminogen activation facilitated by fibrin formation.

In the study of t-PA binding, we measured ${ }^{125}$ I-labeled twochain t-PA bound to immobilized fibrinogen with or without prior treatment with thrombin, and calculated the dissociation constant $\left(K_{\mathrm{d}}\right)$ and the maximal binding $\left(B_{\max }\right)$ from the Scatchard plot analysis data. The $K_{\mathrm{d}}$ and the $B_{\max }$ for thrombintreated fibrinogen Lima were $10.9 \pm 1.2 \times 10^{-8} \mathrm{M}$ and 8.6 \pm 0.6 $\times 10^{-8} \mathrm{M}$, respectively, which were similar to the respective values for the normal sample, $9.5 \pm 1.6 \times 10^{-8} \mathrm{M}$ and $7.9 \pm 0.8$ $\times 10^{-8} \mathrm{M}$. These values are all expressed as mean \pm standard error $(n=7)$. Without prior treatment with thrombin, no substantial binding to t-PA was observed.

We then studied t-PA-catalyzed activation of plasminogen in the presence of polymerizing fibrin monomer derived from the patient's fibrinogen utilizing a plasmin-specific chromogenic substrate, H-D-valine-leucine-lysine-p-nitroanilide (S2251). As depicted in Fig. 7, t-PA-catalyzed plasmin generation in the presence of the polymerizing patient's fibrin monomer was substantially identical with that for the normal control, although fibrin gel formation was distinctly delayed. When the polymerizing fibrin monomer had been replaced with the thrombin-activated patient's fibrinogen (a mixture of thrombin and the patient's fibrinogen), the t-PA-catalyzed plasmin generation was also enhanced in a normal fashion (profiles not shown). The thrombin-activated patient's fibrinogen served also as substrate of the plasmin generated by t-PAcatalyzed plasminogen activation, and was degraded sequentially in a normal fashion, although plasmic fragments $\mathrm{X}, \mathrm{Y}$, and $D\left(D_{1}, D_{2}\right.$, and $\left.D_{3}\right)$ migrated more slowly than the normal counterparts (Fig. 8).

Effect of desialylation on the thrombin clotting of fibrinogen and fibrin monomer polymerization. The patient's and normal fibrinogens were treated with sialidase free of any protease activities. Portions of these samples were further treated with thrombin and desialylated fibrin monomer was prepared. As expected, the sialidase treatment markedly shortened the thrombin time of both normal and the patient's fibrinogen, i.e.,

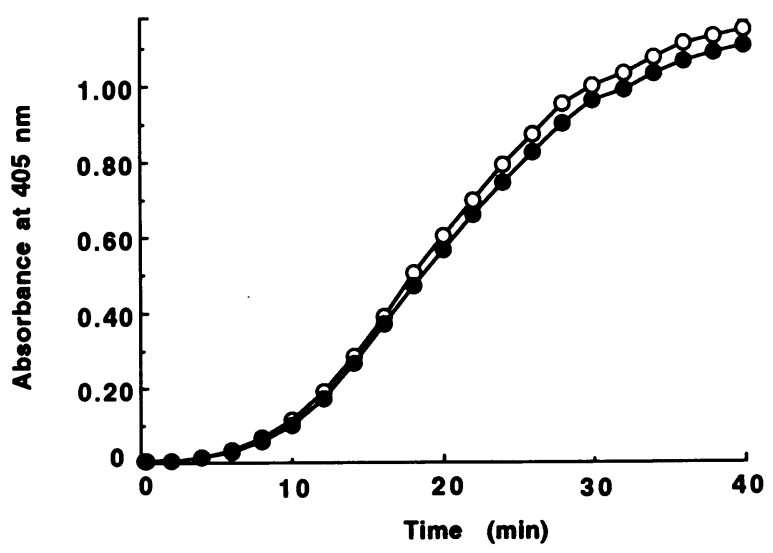

Figure 7. Facilitation of t-PA-catalyzed activation of plasminogen by the polymerizing fibrin monomer. To $180 \mu \mathrm{l}$ of a mixture of plasminogen, two-chain t-PA, and S-2251 in $20 \mathrm{mM}$ Tris- $\mathrm{HCl}$, pH 7.4, containing $0.1 \mathrm{M} \mathrm{NaCl}, 20 \mu$ l of normal $(\mathrm{O})$ or the patient's $(\bullet)$ fibrin monomer in $20 \mathrm{mM}$ acetic acid was added (final concentrations: plasminogen, $0.8 \mu \mathrm{M}$; two-chain t-PA, $40 \mathrm{U} / \mathrm{ml}$; S-2251, $0.3 \mathrm{mM}$; and fibrin monomer, $0.2 \mu \mathrm{M}$ ), and plasmin generation was monitored by the measurement of $A_{405}$ at 1-min intervals. 
$\mathbf{N}$

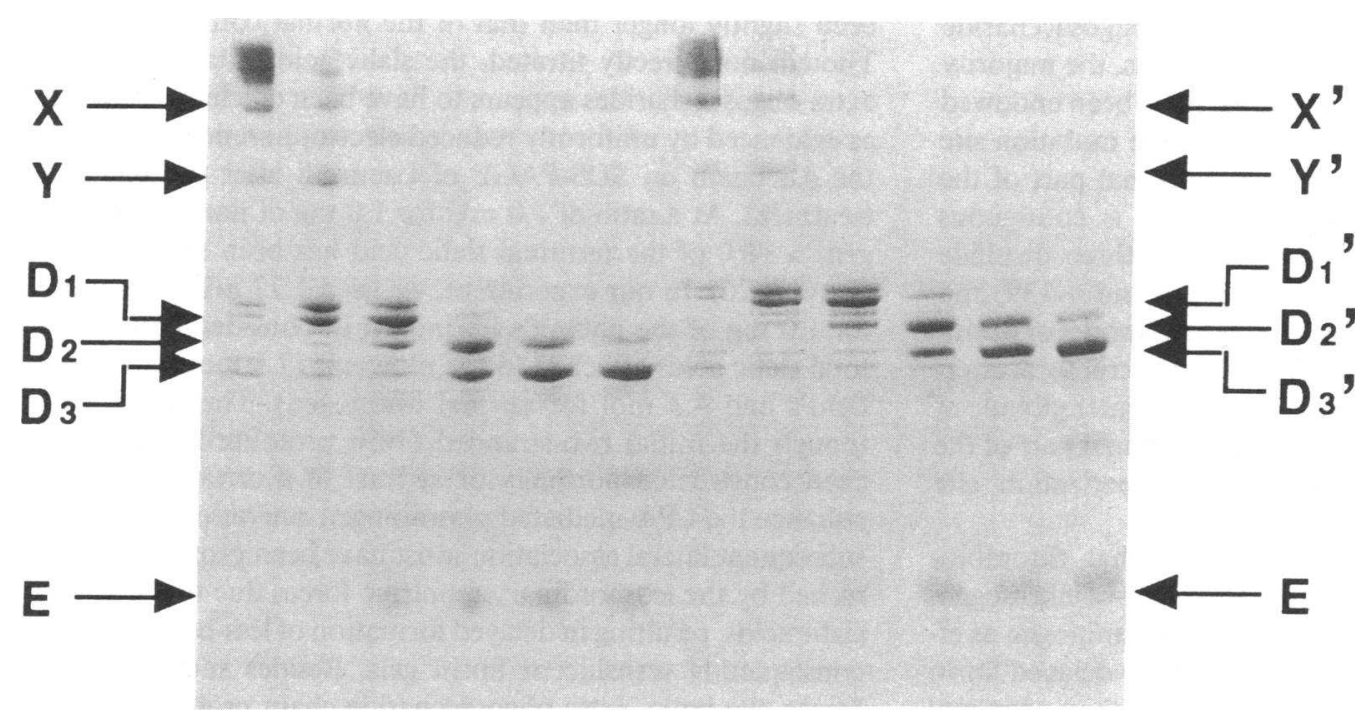

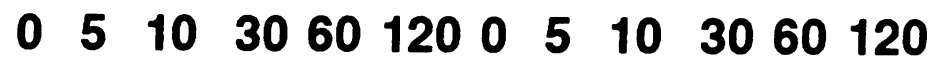
Time (min)
Figure 8. Degradation profiles of thrombin-activated fibrinogen by plasmin generated in its presence by t-PA-catalyzed activation of plasminogen. $N$, thrombinactivated normal fibrinogen; $P$, thrombin-activated patient's fibrinogen. To $10-\mu$ l aliquots of plasminogenenriched normal or the patient's fibrinogen, $5 \mu$ l each of two-chain t-PA and thrombin were simultaneously added (final concentrations: fibrinogen, $1.5 \mu \mathrm{M}$; plasminogen, $0.28 \mu \mathrm{M}$; twochain t-PA, $500 \mathrm{U} / \mathrm{ml}$; and thrombin, $5 \mathrm{NIH} \mathrm{U} / \mathrm{ml}$ ) and the reaction mixtures were incubated at $37^{\circ} \mathrm{C}$. At various intervals, the reaction mixtures were treated with $1 \%$ SDS for $10 \mathrm{~min}$ at $100^{\circ} \mathrm{C}$, and $16 \mu \mathrm{l}$ from each sample was subjected to SDS-PAGE using an 8-25\% gradient gel. The resolved polypeptides were stained with CBB. from 16.2 to $8.4 \mathrm{~s}$ for normal and from 32.4 to $10.2 \mathrm{~s}$ for the patient's fibrinogen.

The fibrin monomer polymerization profile was also improved to nearly a normal profile after the sialidase-treatment as shown in Fig. 9, although the initiation of fibrin polymerization may have been slightly delayed. Thus the sialic acids attached to the extra oligosaccharides appeared to have largely contributed to the delayed fibrin gel formation.

\section{Discussion}

The transition of fibrinogen to fibrin is a highly ordered reaction. This reaction includes release of FPA and FPB by throm-

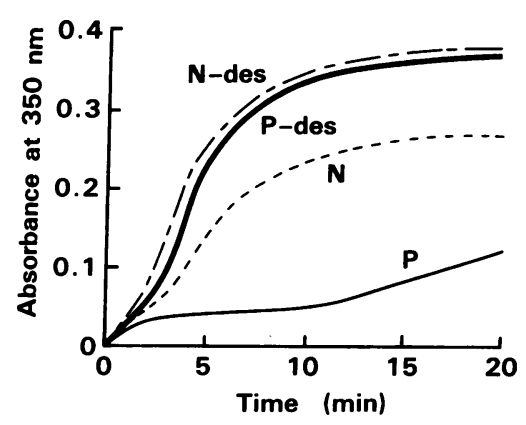

Figure 9. Acceleration of fibrin monomer polymerization after the sialidase-treatment. Normal and the patient's fibrinogen were treated with sialidase $(1.0 \mathrm{mU}$ and $1.77 \mathrm{mU}$ of the enzyme for 1.0 mg each of normal and the abnormal fibrinogen, respectively), and fibrin monomer preparations were harvested essentially as described for the native normal

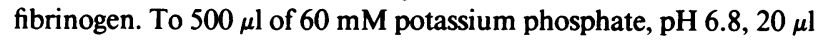
of the normal or the patient's desialylated fibrin monomer in $20 \mathrm{mM}$ acetic acid $\left(A_{280}=5.79\right)$ was added, and fibrin polymerization was monitored by the continuous measurement of $A_{350}$. Curves $N$ and $P$ represent normal and the patient's fibrin monomer before the sialidase-treatment, and curves $\mathrm{N}$-des and $\mathrm{P}$-des those after the sialidasetreatment, respectively. bin, interaction of fibrin monomers to form two-stranded fibrin protofibrils, and their subsequent lateral association to construct appropriately branched fibrin fibers. Intermolecular cross-links between the $\gamma$ chains and those among the multiple $\alpha$ chains are also included in this reaction (1-4). Although these reactions have been extensively studied, there still remain a plethora of enigmas, particularly regarding the mechanisms of fibrin monomer polymerization. Furthermore, transition of fibrinogen to fibrin has been shown to induce a variety of physiologically important functions, and exposure of t-PA binding sites and facilitation of t-PA-catalyzed plasminogen activation are certainly among these functions. To understand these reactions more precisely, abnormal fibrinogens with a well-characterized structural alteration related to the defined functional defects should serve as powerful tools. Indeed, several abnormal fibrinogen molecules have provided much useful information for the better understanding of the structure-function relationships of fibrinogen (see reviews in references 33 and 34).

In this study, we have identified a new type of structural alteration, i.e., an A $\alpha$ arginine-141 to serine substitution associated with extra $\mathrm{N}$-glycosylation at $\mathrm{A} \alpha$ asparagine-139 in a homozygous congenital dysfibrinogen, fibrinogen Lima (5). The extra glycosylation is attributed to a newly created asparagine- $X$-serine/threonine-type consensus sequence, asparaginevaline-serine, for the $\mathrm{N}$-glycosylation of the asparagine residue. This asparagine- $X$-serine-type tripeptide is unique for human fibrinogen, because the glycosylation sequences so far shown for normal (35) and three abnormal fibrinogens $(9,20,36)$ are all asparagine- $X$-threonine types. The extra oligosaccharide in fibrinogen Lima was found to have a biantennary oligosaccharide with a structure of $\mathrm{Gal}_{2} \cdot \mathrm{Man}_{3} \cdot \mathrm{GlCNAc}_{4}$ (see the legend to Fig. 6) mainly represented by a disialylated oligosaccharide comprising $68.6 \%$, and a neutral and a monosialylated oligosac- 
charide accounted for $3.0 \%$ and $28.4 \%$, respectively. This composition is different from that for normal fibrinogen, in which a monosialylated oligosaccharide is the major component comprising $62.5 \%$, and a neutral and a disialylated oligosaccharide represented $15.1 \%$ and $22.4 \%$, respectively. Thus, the majority of the patient's fibrinogen molecules must have been endowed with a strongly negative electric charge near the mutation site on the $A \alpha$ chain located in the carboxy-terminal part of the interdomainal coiled-coil region. This region is contiguous with the second disulfide ring composed of three disulfide bridges between $A \alpha-161$ and $B \beta-197, B \beta-193$ and $\gamma-139$, and $\gamma-135$ and $A \alpha-165$ (29). According to a heptad model of fibrinogen recently proposed by Weisel et al. (4), the structural alteration appears to reside spatially apart from the outer globule of the D domain that comprises the carboxy-terminal part of the $\gamma$ chain containing the putative " $a$ " polymerization site $(30,31)$.

Recently, Suenson et al. (37) observed that thrombintreated fragment $\mathrm{X}$, an early plasmic fragment of fibrinogen, had facilitated t-PA-catalyzed activation of plasminogen as efficiently as normal fibrin despite of significantly delayed fibrin gel formation. On the basis of these findings, they proposed that formation of the initial two-stranded fibrin protofibrils alone rather than coupled to subsequent lateral association was of primary importance for the t-PA-catalyzed plasminogen to plasmin conversion. Very recently, we have also observed the same phenomenon in an abnormal fibrinogen, fibrinogen Caracas II, characterized by impaired fibrin gel formation due to an $A \alpha$-serine- 434 to asparagine substitution accompanied by extra glycosylation at the mutation site itself (20). In light of these findings, the observed normal binding to t-PA and t-PAmediated plasmin generation in fibrinogen Lima (Fig. 7) seem to indicate that the two-stranded fibrin protofibrils were constructed in a normal fashion. This presumption seems to be supported by the observation that isolated fragment $D_{1}$ from the patient's fibrinogen prolonged the thrombin time of normal fibrinogen dose-dependently in a normal fashion, and inhibited polymerization of normal fibrin monomer as efficiently as normal fragment $D_{1}$ (Fig. 4). Thus, the D.E staggering contact among fibrin monomers (3) appears to have taken place normally without the interference by the structural alteration residing in the carboxy-terminal part of the interdomainal coiled-coil region contiguous to the amino-terminus of the D domain. The results also imply that the putative "a" polymerization site specifically assigned to the D domain is located sufficiently apart from the mutation site.

Then how can we account for the delayed formation of fibrin gels which were apparently translucent? Because of a substitution of a basic amino acid arginine to a noncharged hydroxyamino acid serine and attachment of a strongly negative charged extra oligosaccharide (the disialylated, $68.6 \%$, and the monosialylated, $28.4 \%$ ), the majority of the patient's fibrinogen molecules may display extraordinary repulsive forces (38), when they are aligned in such a way that the negatively charged structural alterations would face one another in the step of lateral association of the two-stranded fibrin protofibrils. Indeed, clots from the hyperglycosylated fibrinogen derived from fetal plasma have been shown to assemble more slowly and develop less turbidity $(39,40)$. Conversely, partial or complete desialylation of the hyperglycosylated (41-43) or normal $(38,44,45)$ adult fibrinogen generally resulted in faster fibrin gel formation with higher turbidity. The sialidase treat- ment markedly shortened the thrombin time of this dysfibrinogen from 36.2 to $10.2 \mathrm{~s}$, and greatly improved the fibrin monomer polymerization profile, although the lag time may have been slightly longer than that of the normal control (Fig. 9). Though not directly titrated, the sialic acids attached to the extra oligosaccharides appears to have been efficiently cleaved as evidenced by uniformly reduced electrophoretic mobility of the A $\alpha$ chain on SDS-PAGE of Laemmli after the sialidase treatment. At a ratio of $1.0 \mathrm{mU}$ for $1.0 \mathrm{mg}$ of normal fibrinogen, $>98 \%$ of the terminal sialic acid has been shown to be cleaved (26). In our experiment, we used $1.77 \mathrm{mU}$ of enzyme for $1.0 \mathrm{mg}$ of the patient's fibrinogen in consideration of the total sialic acids attached to the molecule $(7.6 \mathrm{~mol}$ for the patient's and $4.3 \mathrm{~mol}$ for normal fibrinogen). Therefore, even though the initial two-stranded fibrin protofibrils may have been constructed normally or at least to a certain extent to enhance the t-PA-mediated plasminogen activation (37), their subsequent lateral association must have been profoundly perturbed by the extraordinary repulsive forces due to the excess sialic acids, resulting in delayed formation of less-branched and consequently translucent fibrin gels. Besides such repulsive forces, the bulky extra oligosaccharide chain protruding from the polypeptide backbone at position 139 or the point mutation from a basic amino acid arginine to a noncharged amino acid serine at position 141, or both, may have altered the local conformation and have also contributed to the delayed lateral association of fibrin protofibrils. This presumption is based on the slightly longer thrombin time of $10.2 \mathrm{~s}$ than the control value of $8.4 \mathrm{~s}$, and the delayed initiation of fibrin monomer polymerization after removal of the sialic acids (Fig. 9). Complete removal of the extra oligosaccharide chain should give us useful information regarding whether or not the local conformation has been altered by the oligosaccharide chain itself. However, the removal of an asparagine-linked oligosaccharide by glycopeptidase inevitably changes the asparagine residue to an aspartic acid by hydrolyzing the $\beta$-aspartylglycosylamine linkage, as exemplified in Table II. This amino acid exchange gives rise to an extra negative electric charge, and would contribute to the delay in the lateral association of fibrin protofibrils. Thus, this crucial experiment was not feasible in this study.

Considering the structural alteration identified in close proximity to a segment proposed as enhancer for the t-PA-mediated plasminogen activation, i.e., the $A \alpha(148-160)$ residue segment (32), the observed normal t-PA binding and t-PAcatalyzed plasminogen activation appeared to be rather peculiar. The structural integrity with an inherent charge distribution in the specific $A \alpha(148-160)$ residue segment (46) may have been protected from the nearby-located structural alteration upon transition from fibrinogen to fibrin. Or alternatively, another reactive site may have primarily functioned to mask the effect of the structural alteration on the A $\alpha$ chain-assigned reactive site. In fact, a carboxy-terminal segment of the $\gamma$ chain, tentatively assigned to the $\gamma(311-379)$ cyanogen bromide fragment, has recently been proposed to enhance the rate of t-PA-mediated plasminogen activation (47). We have obtained supporting evidence for this hypothesis in two abnormal fibrinogens with a structural alteration in or near this segment, i.e., fibrinogen Kyoto III with a $\gamma$-aspartic acid-330 to tyrosine substitution (48) and fibrinogen Asahi with a $\gamma$-methionine310 to threonine substitution accompanied by an extra oligosaccharide attached to $\gamma$-asparagine-308 (9). In these mutant 
fibrinogens, we have observed significantly decreased t-PA binding $\left(K_{\mathrm{d}}=15.2 \times 10^{-8} \mathrm{M}\right.$ and $17.6 \times 10^{-8} \mathrm{M}$ for fibrinogens Kyoto III and Asahi, respectively, as compared with $9.5 \times 10^{-8}$ $\mathrm{M}$ for normal fibrinogen) and t-PA-mediated plasminogen activation upon treatment with thrombin (manuscript in preparation). Furthermore, these two functions have been shown to be impaired in fibrinogen Nijmegen with a substitution of $B \beta$-arginine-44 to cysteine, resulting in delayed fibrin clot lysis related to venous thrombosis clinically (49). Thus, the normal t-PA binding and t-PA-mediated plasminogen activation observed in fibrinogen Lima may be attributed to this second reactive site, although further studies are necessary for better elucidation of these reactions.

\section{Acknowledgments}

The authors are indebted to Dr. S. Terukina for helpful discussion and to Miss M. Takano for expert secretarial work.

This work was supported in part by Scientific Research Grants-inAid Nos. 63480293 and 02454311 , and Grant-in-Aid for Scientific Research on Priority Areas No. 63616512 from the Ministry of Education, Science and Culture, and Research Grant for Cardiovascular Diseases (2A-1) from the Ministry of Health and Welfare, the Government of Japan to Dr. Matsuda.

\section{References}

1. Blombäck, B., B. Hessel, D. Hogg, and L. Thelkildsen. 1978. A two-step fibrinogen-fibrin transition in blood coagulation. Nature (Lond.). 275:501-505.

2. Laudano, A. P., and R. F. Doolittle. 1978. Synthetic peptide derivatives that bind to fibrinogen and prevent the polymerization of fibrin monomers. Proc. Natl. Acad. Sci. USA. 75:3085-3089.

3. Fowler, W. E., R. R. Hantgan, J. Hermans, and H. P. Erickson. 1981. Structure of the fibrin protofibril. Proc. Natl. Acad. Sci. USA. 78:4872-4876.

4. Weisel, J. W., C. V. Stauffacher, E. Bullitt, and C. Cohen. 1985. A model for fibrinogen: domains and sequence. Science (Wash. DC). 230:3124-3133.

5. Arocha-Piñango, C. L., S. Rodriguez, H. Nagy, and J. L. Perez-Requejo. 1990. Fibrinogen Lima: a new dysfibrinogenemia with a high-molecular weight $\alpha$-chain and defective polymerization. Blood Coagulation and Fibrinolysis. 1:561-565.

6. Matsuda, M., M. Baba, K. Morimoto, and C. Nakamikawa. 1983. Fibrinogen Tokyo II: an abnormal fibrinogen with an impaired polymerization site on the aligned DD domain of fibrin molecules. J. Clin. Invest. 72:1034-1041.

7. Laemmli, U. K. 1970. Cleavage of structural proteins during the assembly of the head of bacteriophage $\mathrm{T}_{4}$. Nature (Lond.). 227:680-685.

8. Weber, K., and M. Osborn. 1969. The reliability of molecular weight determinations by dodecyl sulfate-polyacrylamide gel electrophoresis. J. Biol. Chem. 244:4406-4412.

9. Yamazumi, K., K. Shimura, S. Terukina, N. Takahashi, and M. Matsuda. 1989. A $\gamma$ methionine-310 to threonine substitution and consequent $N$-glycosylation at $\gamma$ asparagine- 308 identified in a congenital dysfibrinogenemia associated with posttraumatic bleeding, fibrinogen Asahi. J. Clin. Invest. 83:1590-1597.

10. Deutsch, D. G., and E. T. Mertz. 1970. Plasminogen: purification from human plasma by affinity chromatography. Science (Wash. DC). 170:10951096.

11. Lorand, D., R. B. Credo, and T. J. Janus. 1981. Factor XIII (fibrin-stabilizing factor). Methods Enzymol. 80:333-341.

12. Lundblad, R. L. 1971. A rapid method for the purification of bovine thrombin and the inhibition of the purified enzyme with phenylmethylsulfonyl fluoride. Biochemistry. 10:2501-2506.

13. Marder, V. J., N. R. Shulman, and W. F. Carroll. 1969. High molecular weight derivatives of human fibrinogen produced by plasmin. I. Physicochemical and immunological characterization. J. Biol. Chem. 244:2111-2119.

14. Gollwitzer, R., R. Timpl, U. Becker, and H. Furthmayr. 1972. Chemical and immunological properties of reduced and alkylated polypeptide chains of bovine fibrinogen. Eur. J. Biochem. 28:497-506.

15. Barlow, G. H., L. Summaria, and K. C. Robbins. 1969. Molecular weight studies on human plasminogen and plasmin at the $\mu \mathrm{g}$ level. J. Biol. Chem. 244:1138-1141.

16. Shwartz, M. L., S. V. Pizzo, R. L. Hill, and P. A. Mckee. 1973. Human factor XIII from plasma and platelets. J. Biol. Chem. 248:1395-1407.

17. Kehl, M., F. Lottspeich, and A. Henschen. 1981. Analysis of human fibrinopeptides by high-performance liquid chromatography. Hoppe-Seyler's Z. Physiol. Chem. 362:1661-1664.

18. Haverkate, F., J. Koopman, C. Kluft, A. D'Angelo, M. Cottaneo, and P. M. Mannucci. 1986. Fibrinogen Milano II: a congenital dysfibrinogenemia associated with juvenile arterial and venous thrombosis. Thromb. Haemostasis. 55:131-135

19. Terukina, S., M. Matsuda, H. Hirata, Y. Takeda, T. Miyata, T. Takao, and Y. Shimonishi. 1988. Substitution of $\gamma$ Arg-275 by Cys in an abnormal fibrinogen, "fibrinogen Osaka II": evidence for a unique solitary cystine structure at the mutation site. J. Biol. Chem. 263:13579-13587.

20. Maekawa, H., K. Yamazumi, S. Muramatsu, M. Kaneko, H. Hirata, N. Takahashi, N. B. de Bosch, Z. Carvajal, A. Ojeda, C. L. Arocha-Piñango, and M. Matsuda. 1991. An A $\alpha$ Ser-434 to $N$-glycosylated Asn substitution in a dysfibrinogen, fibrinogen Caracas II, characterized by impaired fibrin gel formation. $J$. Biol. Chem. 266:11575-11581.

21. Hewick, R. M., M. W. Hunkapiller, L. E. Hood, and W. J. Dreyer. 1981. A gas-liquid solid phase peptide and protein sequenator. J. Biol. Chem. 256:79907997.

22. Tomiya, N., M. Kurono, H. Ishihara, S. Tejima, S. Endo, Y. Arata, and N. Takahashi. 1987. Structural analysis of $N$-linked oligosaccharides by a combination of glycopeptidase, exoglycosidases, and high-performance liquid chromatography. Anal. Biochem. 163:489-499.

23. Tomiya, N., J. Awaya, M. Kurono, S. Endo, Y. Arata, and N. Takahashi. 1988. Analysis of $\mathrm{N}$-linked oligosaccharides using a two-dimensional mapping technique. Anal. Biochem. 171:73-90.

24. Hase, S., T. Ibuki, and T. Ikenaka. 1984. Reexamination of the pyridylamination used for fluorescence labeling of oligosaccharides and its application to glycoproteins. J. Biochem. (Tokyo). 95:197-203.

25. Townsend, R. R., M. R. Hardy, O. Hindsgual, and Y. C. Lee. 1988. High-performance anion-exchange chromatography of oligosaccharides using pellicular resins and pulsed amperometric detection. Anal. Biochem. 174:459470.

26. Nishibe, H., and N. Takahashi. 1981. The release of carbohydrate moieties from human fibrinogen by almond glycopeptidase without alteration in fibrinogen clottability. Biochim. Biophys. Acta. 661:274-279.

27. Clauss, A. 1957. Gerinnungsphysiologische Schnellmethode zur Bestimmung des Fibrinogens. Acta Haematol. (Basel). 17:237-247.

28. Ingram, G. I. C., and M. O. Matchett. 1960. A rapid "side-room" method for determination of plasma fibrinogen concentration as fibrin. J. Clin. Pathol. 13:469-471.

29. Doolittle, R. F. 1973. Structural aspects of the fibrinogen-fibrin conversion. Adv. Protein Chem. 27:1-109.

30. Kudryk, B., D. Collen, K. R. Woods, and B. Blombäck. 1974. Evidence for localization of polymerization sites in fibrinogen. J. Biol. Chem. 249:33223325 .

31. Olexa, S. A., and A. Z. Budzynski. 1980. Evidence for four different polymerization sites involved in human fibrin formation. Proc. Natl. Acad. Sci. USA. 77:1374-1378.

32. Voskuilen, M., A. Vermond, G. H. Veeneman, J. H. van Boom, E. A. Klasen, N. D. Zegers, and W. Nieuwenhuizen. 1987. Fibrinogen lysine residue A $\alpha 157$ plays a crucial role in the fibrin-induced acceleration of plasminogen activation, catalyzed by tissue-type plasminogen activator. J. Biol. Chem. 262:5944-5946.

33. Southan, C. 1988. Molecular and genetic abnormalities of fibrinogen. In Fibrinogen, Fibrin Stabilisation and Fibrinolysis: Clinical, Biochemical and Laboratory Aspects. J. L. Francis, editor. Ellis Horwood, Chichester. 65-99.

34. Matsuda, M., N. Yoshida, S. Terukina, K. Yamazumi, and H. Maekawa. 1990. Molecular abnormalities of fibrinogen-the present status of structure elucidation. In Fibrinogen 4: Current Basic and Clinical Aspects. M. Matsuda, S. Iwanaga, A. Takada, and A. Henschen, editors. Excerpta Medica, Amsterdam. $139-152$.

35. Townsend, R. R., E. Hilliker, Y.-T. Li, R. A. Laine, W. R. Bell, and Y. C. Lee. 1982. Carbohydrate structure of human fibrinogen. J. Biol. Chem. 257:9704-9710.

36. Kaudewitz, H., A. Henschen, J. Soria, and C. Soria. 1986. Fibrinogen Pontoise-a genetically abnormal fibrinogen with defective fibrin polymerization but normal fibrinopeptide release. In Fibrin Formation and Fibrinolysis. Fibrinogen. 4:91-96.

37. Suenson, E., P. Bjerrum, A. Holm, B. Lind, M. Meldal, J. Selmer, and L. C. Petersen. 1990. The role of fragment X polymers in the fibrin enhancement of tissue plasminogen activator-catalyzed plasmin formation. J. Biol. Chem. 265:22228-22237.

38. Langer, B. G., J. W. Weisel, P. A. Dinauer, C. Nagaswami, and N. R. Bell. 1988. Deglycosylation of fibrinogen accelerates polymerization and increases lateral aggregation of fibrin fibers. J. Biol. Chem. 263:15056-15063.

39. Galanakis, D., and M. W. Mosesson. 1976. Evaluation of the role of in vivo proteolysis(fibrinogenolysis) in prolonging the thrombin time of human umbilical cord fibrinogen. Blood. 48:109-118.

40. Tesch, R., R. Trolp, and I. Witt. 1979. Electron microscopic studies on the foetal fibrin clot. Thromb. Res. 16:239-243. 
41. Galanakis, D., J. Martinez, C. McDevitt, and F. Miller. 1983. Human fetal fibrinogen: its characteristics of delayed fibrin formation, high sialic acid and AP peptide content are more marked in pre-term than in term samples. Ann. N. Y. Acad. Sci. 408:640-643.

42. Martinez, J., J. E. Palascak, and D. Kwasniak. 1978. Abnormal sialic acid content of the dysfibrinogenemia associated with liver disease. J. Clin. Invest. 61:535-538.

43. Martinez, J., K. A. MacDonald, and J. E. Palascak. 1983. The role of sialic acid in the dysfibrinogenemia associated with liver disease: distribution of sialic acid on the constituent chains. Blood. 61:1196-1202.

44. Martinez, J., J. E. Palascak, and C. Peters. 1977. Functional and metabolic properties of human asialofibrinogen. J. Lab. Clin. Med. 89:367-377.

45. Park, K., S. J. Gendt, and S. L. Cooper. 1986. The effect of fibrinogen sialic acid residues on ex vivo platelet deposition on biomaterials. Thromb. Res. 43:293-302.

46. Schielen, W. J. G., M. Voskuilen, P. J. H. M. Adams, G. I. Tesser, and W.
Nieuwenhuizen. 1990. Structural requirements of fibrinogen $A \alpha-(148-160)$ for the enhancement of the rate of plasminogen activation by tPA. Blood Coagulation and Fibrinolysis. 1:521-524.

47. Yonekawa, O., A. Vermond, and W. Nieuwenhuizen. 1990. Localization of a new site in fibrin, involved in the acceleration of the tissue-type plasminogen àctivator (t-PA)-catalyzed activation of plasminogen. In Fibrinogen 4. Current Basic and Clinical Aspects. M. Matsuda, S. Iwanaga, A. Takada, and A. Henschen, editors. Excerpta Medica, Amsterdam. 111-116.

48. Terukina, S., K. Yamazumi, K. Okamoto, H. Yamashita, Y. Ito, and M Matsuda. 1989. Fibrinogen Kyoto III: a congenital dysfibrinogen with a $\gamma$ aspartic acid-330 to tyrosine substitution manifesting impaired fibrin monomer polymerization. Blood. 74:2681-2687.

49. Engesser, L., J. Koopman, G. de Hunk, F. Haverkate, I. Novakova, J. H. Verheijen, E. Briet, and E. J. P. Brommer. 1988. Fibrinogen Nijmegen: congenital dysfibrinogenemia associated with impaired t-PA mediated plasminogen activation and decreased binding of t-PA. Thromb. Haemostasis. 60:113-120. 